\title{
The predictive value of high-density lipoprotein for ocular metastases in colorectal cancer patients
}

This article was published in the following Dove Press journal:

Cancer Management and Research

\author{
Pei-Wen Zhu* \\ Ying-Xin Gong* \\ You-Lan Min \\ Qi Lin \\ Biao Li \\ Wen-Qing Shi \\ Qing Yuan \\ Lei Ye \\ Yi Shao
}

Department of Ophthalmology, The First Affiliated Hospital of Nanchang University, Jiangxi Province Ocular Disease Clinical Research Center, Nanchang 330006, Jiangxi, People's Republic of China

*These authors have contributed equally to this work
Correspondence: Yi Shao

Department of Ophthalmology, The First Affiliated Hospital of Nanchang

University, No. 17 Yongwaizheng Street,

Donghu District, Nanchang 330006,

Jiangxi, People's Republic of China

$\mathrm{Tel} / \mathrm{Fax}+08679188692520$

Email freebee99@।63.com
Purpose: Colorectal cancer (CRC) is a common tumor of the digestive tract that tends to metastasize and leads to high mortality. Ocular metastases (OM) from colorectal cancer are being increasingly diagnosed, and they can lead to a poor prognosis. Serum lipids are a known risk factor for cardiovascular disease, and are also relevant to the occurrence of CRC. In this study, we examined the levels of serum lipids and tried to determine whether there were correlations with the occurrence of $\mathrm{OM}$ in patients with colorectal cancer, in order to determine whether serum lipid levels may be a risk factor for OM in this patient population.

Patients and methods: Records from a total of 703 patients treated for colorectal cancer from August 2005 to August 2017 were involved in this study. Student's $t$-tests, nonparametric rank sum tests, and Chi-square tests were applied to describe whether there were significant differences between the OM group and non-ocular metastases (NOM) group. We used binary logistic regression analysis to determine the risk factors and receiver operating curve (ROC) analyses to assess the diagnostic value for OM in CRC patients.

Results: There were no significant differences in gender, age, histopathology type, or tumor classifications between the OM and NOM groups. The levels of serum TC, HDL, and LDL were significantly different between patients with and without lymph node metastases as well as male and female patients. The OM group had higher serum HDL levels compared to the NOM group. Binary logistic regression indicated that HDL was a risk factor for $\mathrm{OM}$ in colorectal cancer patients. The ROC curves showed that the AUC of HDL was 0.660. The cutoff value of HDL was $1.27 \mathrm{mmol} / \mathrm{L}$, with a sensitivity of 0.619 and a specificity of 0.650 . Conclusion: HDL levels are correlated with ocular metastases in colorectal cancer patients. Keywords: high-density lipoprotein, ocular metastases, colorectal cancer, independent risk factor

\section{Introduction}

As the third most frequently diagnosed neoplasm, colorectal cancer (CRC) is the main cause of cancer mortality in many countries. ${ }^{1,2}$ Studies have shown that dietary intake and physical activity are closely related to the incidence of CRC. ${ }^{3}$ As a result of modern Asian dietary patterns, the morbidity of CRC is increasingly high. ${ }^{4}$

Metastatic disease occurs frequently in colorectal cancer patients, with lesions found in the liver $(77 \%)$, peritoneum $(25 \%)$, and lungs $(22 \%)$ most frequently. ${ }^{5}$ Until recently, ocular metastases (OM) were considered to be rare in CRC patients. However, it appears that $\mathrm{OM}$ are becoming increasingly common. ${ }^{6}$ Moreover, these OM can produce symptoms such as eye pain, peculiar ocular sensations, blurred vision, and visual field defects, severely affecting the patients' quality of life.' Given this, it is important to diagnose $\mathrm{OM}$ when they occur. 
Currently, several methods are utilized to diagnose CRC, including stool tests that function as a preliminary screen for these cancers; endoscopy (flexible sigmoidoscopy or colonoscopy) for visual inspection/biopsy and tissue diagnosis; radiological studies such as CT colonography or doublecontrast barium enemas to identify precancerous tumors. ${ }^{8}$ However, the majority of these methods are invasive, timeconsuming and have low or limited sensitivity. Development of a simple noninvasive but sensitive diagnostic technique would be of great benefit to clinical medicine, and it could promote better patient acceptance of colon cancer screening. ${ }^{9}$

Blood lipid levels have been of great concern ever since their epidemiologic relationships to cardiovascular disease were established. But recently Zhang et $\mathrm{a}^{10}$ found that lipid levels in the serum and neoplastic tissue of CRC patients may be relevant to the onset and advancement of their tumors. Animal experiments have demonstrated that some kinds of serum lipids can affect the growth of tumors via modulating immune cell function. ${ }^{11}$ Moreover, serum lipid levels have also been used to clinically assess the prognosis of several cancers. $^{12,13}$ Several studies have shown associations between hyperlipidemia and risks of CRC, and it is known that cholesterol plays a crucial role in cancer metabolism. ${ }^{14,15}$ However, whether there is a correlation between OM and serum lipid levels in colorectal cancer patients remains uncertain.

In the present investigation, we conducted a retrospective chart review to begin to determine whether there is a relationship between serum lipid levels and ocular metastases in CRC patients, and also to begin to elucidate possible risk factors for developing OM.

\section{Materials and methods Study design}

This study was performed with the approval of the medical research ethics committee of the First Affiliated Hospital of Nanchang University. The methods used in this study were guided by the relevant guidelines and regulations, and the study was conducted in accordance with the Declaration of Helsinki. A consecutive series of patients treated between August 2005 and August 2017 for unequivocal diagnoses of CRC were qualified and became subjects of the study. Their medical records were compiled and reviewed. Secondary colorectal cancer patients were excluded from the study. Both the OM and NOM patients had diagnoses of CRC that had been confirmed by histopathological findings from surgical resections or biopsy samples. The OM lesions were identified by CT or MRI scans. The exclusion criteria for the OM group included: 1) patients with primary ocular malignant tumors; 2) ocular benign tumors; 3 ) colorectal cancer patients with only other distant metastases (eg, lung, bone, liver, or brain). NOM patients were excluded ocular lesion by eye tests.

\section{Data collection}

Relevant clinical data were collected retrospectively from each subject's medical records. The relevant information included age, gender, histopathologic types, tumor classification, metastatic sites, domiciles of patients, and the levels of serum lipids detected, including total cholesterol (TC), triglyceride (TG), high-density lipoprotein (HDL), and low-density lipoprotein (LDL). All these parameters were collected at the time that the initial diagnosis of colorectal cancer was made.

\section{Statistical analysis}

Student's t-tests, nonparametric rank sum tests (MannWhitney tests), and Chi-square tests were utilized to determine whether there were significant differences in the clinical features between the $\mathrm{OM}$ and NOM patients. Then binary logistic regression models were built to clarify the independent risk factors for ocular metastases. In order to estimate the accuracy of the OM predictions, receiver operating characteristic (ROC) curves were calculated and the areas under the curves (AUC) were calculated. A $P$-value $<0.05$ was considered to be statistically significant. Statistical analyses were performed using SPSS version 18.0 software (SPSS Inc., Chicago, IL, USA), MedCalc18.6.0 statistical software (MedCalc, Ostend, Belgium), and Excel 2010 software (Excel, Microsoft Corporation, Redmond, WA, USA). Continuous data were displayed in a form of means \pm SD.

\section{Results}

\section{Demographics and clinical characteristics}

The records of 703 patients (431 men and 272 women) were reviewed in this study, representing 21 cases of $\mathrm{OM}$ (16 with orbital metastases and 5 with intraocular metastases) and 682 cases of NOM. There were no significant differences between the OM and NOM groups with respect to gender, age, histopathology type, or tumor classification by Chi-square test and nonparametric rank sum tests. The average ages of the OM and NOM cases were 
similar, at $57.6 \pm 12.1$ and $58.6 \pm 13.5$ years, respectively. Most of the subjects were diagnosed with adenocarcinomas (564 cases, 80.2\%). None of the subjects with OM had lymph node metastases (LNM). The detailed clinical features of all subjects in the study are shown in Table 1. Figure 1 shows that most of the patients were from Jiangxi Province and nearly half of them were from the provincial capital of Nanchang. Some patients developed metastases to organs other than to the eyes, with liver, lung, and brain being the three most common sites.

\section{Differences of the clinical features and the risk factors of ocular metastases}

Because none of the subjects with OM in this study had LNM, we divided the entire cohort into a LNM (+) group and non-lymph node metastases (NLNM) group, and found that the mean levels of TC, HDL, and LDL were significantly different between the two groups. There were also significant differences based on gender (Table 2). Moreover, significantly higher HDL levels occurred in OM than NOM subjects (Table 3) who were males, had NLNM, or were males with non-lymph node metastases, or were included in the whole group. However, in the female subjects, there were no significant differences between the OM and NOM subgroups. Binary logistic regression modeling showed that HDL was an independent risk factor for OM. The detailed result is shown in Table 4.

\section{The cut-off value, AUC, sensitivity and specificity of HDL for diagnosing ocular metastases}

As shown in Figure 2, the ROC curves shared the same cutoff value, which was $1.27 \mathrm{mmol} / \mathrm{L}$ for HDL regardless of the method of classification. For the NLNM + men, the AUC was 0.699 for HDL, which was the most accurate differentiating factor found for the OM and NOM subjects, with a sensitivity and specificity of 0.562 and 0.740 , respectively. The calculations for the whole sample led to an AUC of 0.660 , with a sensitivity of 0.619 and a specificity of 0.650 . All these results were statistically significant.

\section{Discussion}

Colorectal cancer is one of the most common cancers worldwide, accounting for about $8.5 \%$ of all cancer mortality and $10 \%$ of new cases. ${ }^{16}$ Once metastasis of a colorectal cancer has occurred, the disease is usually fatal. Therefore, failure to detect and treat the cancer in a timely fashion can result in high mortality. About $20 \%$ of CRC patients have metastases

Table I The clinical characteristics of patients with colorectal cancer

\begin{tabular}{|c|c|c|c|c|}
\hline Patient characteristics & $\begin{array}{l}\text { OM group }^{a}(\%) \\
(n=2 I)\end{array}$ & $\begin{array}{l}\text { NOM group (\%) } \\
(n=682)\end{array}$ & $\begin{array}{l}\text { Total number of patients }(\%) \\
(n=703)\end{array}$ & $P$-value ${ }^{d}$ \\
\hline $\begin{array}{l}\text { Gender }^{\mathrm{b}} \\
\text { Male } \\
\text { Female }\end{array}$ & $\begin{array}{l}16(76.2) \\
5(23.8)\end{array}$ & $\begin{array}{l}415(60.9) \\
267(39.1)\end{array}$ & $\begin{array}{l}431(61.3) \\
272(38.7)\end{array}$ & 0.155 \\
\hline $\begin{array}{l}\text { Age }(\text { years })^{c} \\
\text { Mean }\end{array}$ & $57.6 \pm 12.1$ & $58.6 \pm 13.5$ & $58.5 \pm 13.5$ & 0.751 \\
\hline $\begin{array}{l}\text { Histopathological type } \\
\text { Adenocarcinoma } \\
\text { Mucinous adenocarcinoma } \\
\text { Signet-ring cell carcinoma } \\
\text { Unknown }\end{array}$ & $\begin{array}{l}15(71.4) \\
2(9.5) \\
0(0.0) \\
4(19.1)\end{array}$ & $\begin{array}{l}549(80.5) \\
75(11.0) \\
7(1.0) \\
51(7.5)\end{array}$ & $\begin{array}{l}564(80.2) \\
77(11.0) \\
7(1.0) \\
55(7.8)\end{array}$ & 0.267 \\
\hline $\begin{array}{l}\text { Tumor classification }{ }^{\mathrm{b}} \\
\text { Colon cancer } \\
\text { Rectal cancer } \\
\text { Unknown }\end{array}$ & $\begin{array}{l}9(42.9) \\
10(47.6) \\
2(9.5)\end{array}$ & $\begin{array}{l}302(44.3) \\
361(52.9) \\
19(2.8)\end{array}$ & $\begin{array}{l}311(44.2) \\
37 \mid(52.8) \\
21(3.0)\end{array}$ & 0.200 \\
\hline $\begin{array}{l}\text { Lymph node metastasis } \\
\text { With } \\
\text { Without }\end{array}$ & $\begin{array}{l}0 \\
21\end{array}$ & $\begin{array}{l}250 \\
432\end{array}$ & $\begin{array}{l}250 \\
453\end{array}$ & \\
\hline
\end{tabular}

Notes: ${ }^{\mathrm{a} O M}$ group included 16 orbital metastasis cases and 5 intraocular metastasis cases. ${ }^{\mathrm{b}} \mathrm{Chi}-\mathrm{square}$ test was used. ${ }^{\mathrm{C}}$ Nonparametric sum up test was used. ${ }^{\mathrm{d}}$ Comparison between OM group and NOM metastases group. $P<0.05$ was considered statistically significant.

Abbreviations: OM, ocular metastasis; NOM, non-ocular metastasis. 


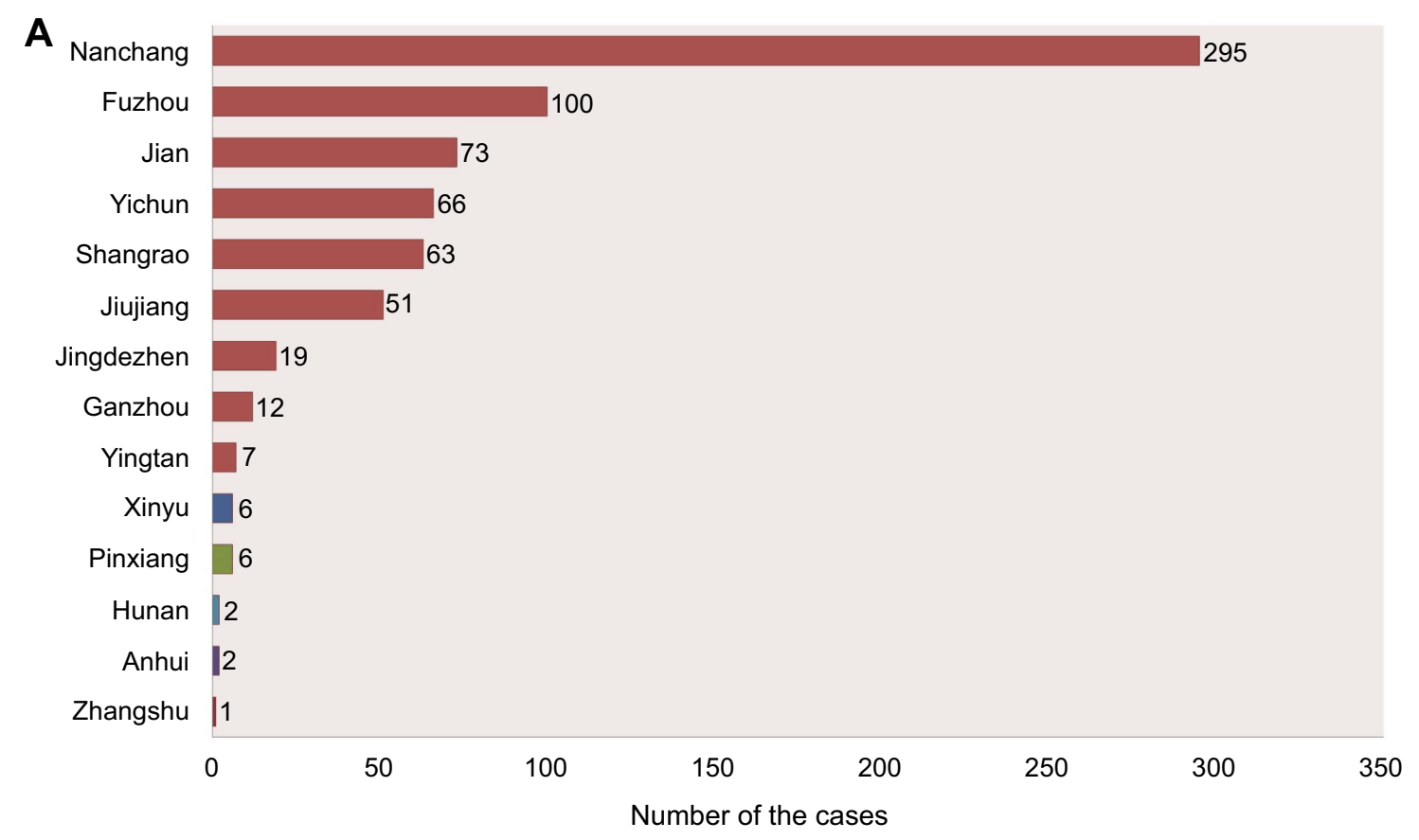

B

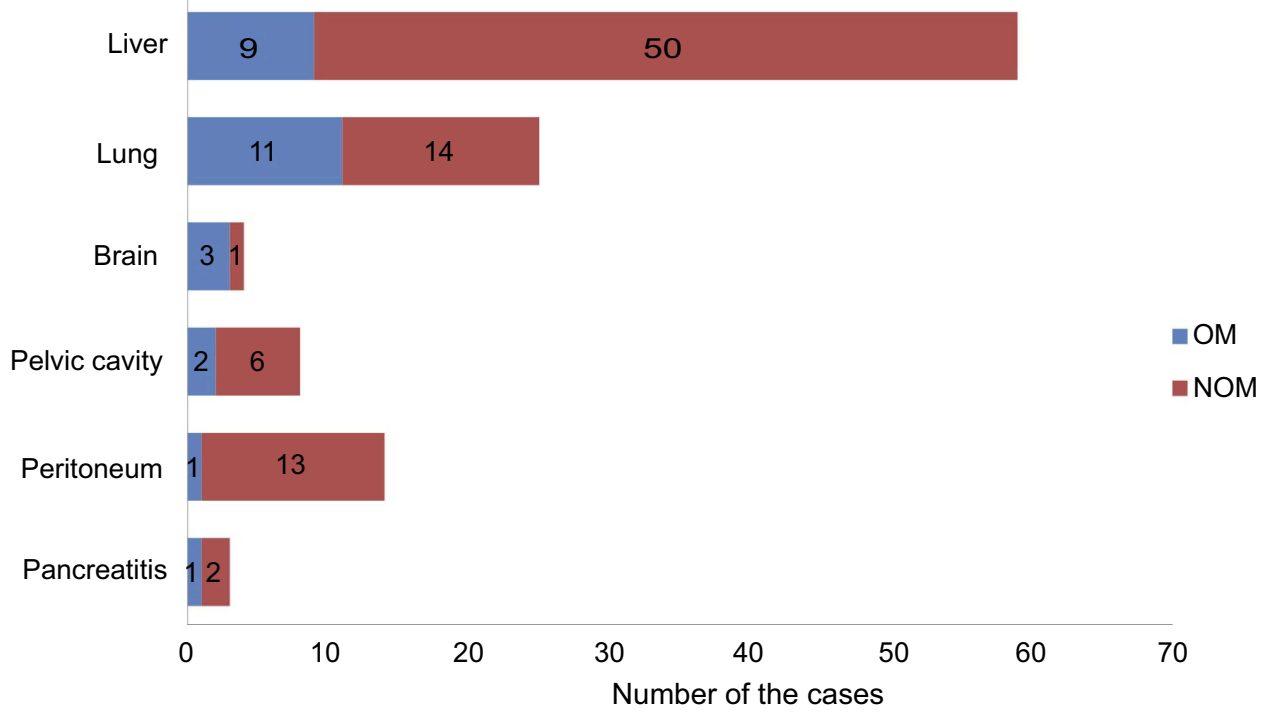

Figure I Clinical features of colorectal cancer patients involved.

when their diagnosis is made, and $35-45 \%$ of patients with apparently non-metastatic disease relapse within 5 years after surgery. Most of these patients with recurrences had undiscovered preoperative metastases. ${ }^{17}$ These studies suggest that the underlying cause of a failure to make an early diagnosis of CRC metastases is a lack of sensitivity of the screening protocols.

The incidence rates of ocular metastases from CRC are low compared to those of liver and lung metastases, ${ }^{5}$ but it appears that diagnoses of ocular lesions are becoming increasingly common. In 2004, Linares et $\mathrm{al}^{18}$ reported the case of a 47 year-old male with bilateral choroidal metastases as the initial manifestation of a rectal cancer. In 2008, Kuo et $\mathrm{al}^{19}$ reported a 65 year-old woman with a subfoveal choroidal metastases from a colorectal adenocarcinoma. Moreover, $\mathrm{OM}$ at that time was a sign of a poor prognosis for patients with various types of cancer. According to a study by Shields et $\mathrm{al}^{20}$ of 420 patients in 1997, ocular metastases occurred in 196 patients with breast cancer (47\%), 90 with lung cancer (21\%), 18 with gastrointestinal neoplasms (4\%), 9 with kidney cancer (2\%), 9 with skin cancers $(2 \%), 9$ with prostate cancer $(2 \%)$, and 16 from primary 
Table 2 The differences of serum lipids between patients in different clinical characteristics

\begin{tabular}{|l|l|l|l|l|}
\hline Clinical characteristics & TC $(\mathbf{m m o l} / \mathbf{L})$ & TG $(\mathbf{m m o l} / \mathbf{L})$ & HDL $(\mathbf{m m o l} / \mathbf{L})$ & LDL $(\mathbf{m m o l} / \mathbf{L})$ \\
\hline Lymph node metastasis & & & & \\
LNM group $(\mathrm{n}=250)$ & $4.39 \pm 1.03$ & $1.24 \pm 0.59$ & $1.24 \pm 0.37$ & $2.66 \pm 0.87$ \\
NLNM group $(\mathrm{n}=453)$ & $4.15 \pm 0.96$ & $1.28 \pm 1.68$ & $1.17 \pm 0.37$ & $2.49 \pm 0.78$ \\
\hline$t$ & 3.143 & -0.367 & 2.475 & 2.652 \\
$P$-value & 0.002 & 0.714 & 0.014 & 0.008 \\
\hline Gender & & & & $2.14 \pm 0.35$ \\
Male $(\mathrm{n}=250)$ & $4.11 \pm 0.96$ & $1.27 \pm 1.69$ & $1.27 \pm 0.39$ & $2.64 \pm 0.81$ \\
Female $(\mathrm{n}=453)$ & $4.42 \pm 1.02$ & $1.27 \pm 0.71$ & -4.853 & -2.348 \\
\hline$t$ & -4.016 & -0.052 & $<0.001$ & 0.019 \\
$P$-value & $<0.001$ & 0.958 & \\
\hline
\end{tabular}

Note: $P<0.05$.

Abbreviations: LNM, lymph node metastasis; NLNM, non-lymph node metastasis; TC, total cholesterol; TG, triglyceride; HDL, high-density lipoprotein; LDL, low-density lipoprotein.

cancers of other sites (4\%). The diagnostic techniques commonly available today such as CT and MRI are timeconsuming and expensive, and have limited sensitivity and

Table 3 The differences of clinical recognized serum tumor markers between patients with and without OM under different classifications

\begin{tabular}{|c|c|c|c|c|}
\hline \multicolumn{5}{|c|}{ A. Non-lymph node metastasis } \\
\hline $\begin{array}{l}\text { Clinical } \\
\text { features }\end{array}$ & $\begin{array}{l}\text { OM } \\
\text { group } \\
(n=21)\end{array}$ & $\begin{array}{l}\text { NOM } \\
\text { group } \\
(n=432)\end{array}$ & $t$ & $P$-value \\
\hline TC (mmol/L) & $4.26 \pm 0.52$ & $4.14 \pm 0.98$ & 0.952 & 0.350 \\
\hline TG (mmol/L) & $1.16 \pm 0.47$ & $1.29 \pm 1.72$ & -0.350 & 0.727 \\
\hline $\mathrm{HDL}(\mathrm{mmol} / \mathrm{L})$ & $1.38 \pm 0.34$ & $1.16 \pm 0.37$ & 2.695 & 0.007 \\
\hline LDL (mmol/L) & $2.39 \pm 0.39$ & $2.50 \pm 0.79$ & -1.220 & 0.233 \\
\hline \multicolumn{5}{|l|}{ B. Female } \\
\hline $\begin{array}{l}\text { Clinical } \\
\text { features }\end{array}$ & $\begin{array}{l}\text { OM } \\
\text { group } \\
(n=5)\end{array}$ & $\begin{array}{l}\text { NOM } \\
\text { group } \\
(n=267)\end{array}$ & $t$ & $P$-value \\
\hline $\mathrm{TC}(\mathrm{mmol} / \mathrm{L})$ & $4.26 \pm 0.46$ & $4.42 \pm 1.03$ & -0.363 & 0.717 \\
\hline TG $(\mathrm{mmol} / \mathrm{L})$ & $0.98 \pm 0.27$ & $1.28 \pm 0.72$ & -0.930 & 0.353 \\
\hline $\mathrm{HDL}(\mathrm{mmol} / \mathrm{L})$ & $1.50 \pm 0.29$ & $1.28 \pm 0.39$ & 1.285 & 0.200 \\
\hline LDL (mmol/L) & $2.63 \pm 0.18$ & $2.65 \pm 0.82$ & -0.141 & 0.891 \\
\hline \multicolumn{5}{|l|}{ C. Male } \\
\hline $\begin{array}{l}\text { Clinical } \\
\text { features }\end{array}$ & $\begin{array}{l}\text { OM } \\
\text { group } \\
(n=16)\end{array}$ & $\begin{array}{l}\text { NOM } \\
\text { group } \\
(n=4 \mid 5)\end{array}$ & $t$ & $P$-value \\
\hline $\mathrm{TC}(\mathrm{mmol} / \mathrm{L})$ & $4.26 \pm 0.55$ & $4.11 \pm 0.97$ & 1.021 & 0.320 \\
\hline TG (mmol/L) & $1.21 \pm 0.52$ & $1.27 \pm 1.72$ & -0.128 & 0.898 \\
\hline $\mathrm{HDL}(\mathrm{mmol} / \mathrm{L})$ & $1.34 \pm 0.36$ & $1.13 \pm 0.35$ & 2.345 & 0.019 \\
\hline LDL (mmol/L) & $2.3 I \pm 0.4 I$ & $2.50 \pm 0.82$ & -1.772 & 0.092 \\
\hline
\end{tabular}

(Continued)
Table 3 (Continued).

\begin{tabular}{|c|c|c|c|c|}
\hline \multicolumn{5}{|c|}{ D. Non-lymph node metastasis + male } \\
\hline $\begin{array}{l}\text { Clinical } \\
\text { features }\end{array}$ & $\begin{array}{l}\text { OM } \\
\text { group } \\
(n=16)\end{array}$ & $\begin{array}{l}\text { NOM } \\
\text { group } \\
(n=258)\end{array}$ & $t$ & $P$-value \\
\hline $\mathrm{TC}(\mathrm{mmol} / \mathrm{L})$ & $4.26 \pm 0.55$ & $4.01 \pm 0.89$ & 1.701 & 0.104 \\
\hline TG (mmol/L) & $1.21 \pm 0.52$ & $1.29 \pm 2.13$ & -0.152 & 0.880 \\
\hline $\mathrm{HDL}(\mathrm{mmol} / \mathrm{L})$ & $1.34 \pm 0.36$ & $1.10 \pm 0.34$ & 2.733 & 0.007 \\
\hline LDL (mmol/L) & $2.31 \pm 0.41$ & $2.44 \pm 0.76$ & -1.188 & 0.247 \\
\hline \multicolumn{5}{|l|}{ E. Whole } \\
\hline $\begin{array}{l}\text { Clinical } \\
\text { features }\end{array}$ & $\begin{array}{l}\text { OM } \\
\text { group } \\
(n=2 I)\end{array}$ & $\begin{array}{l}\text { NOM } \\
\text { group } \\
(n=682)\end{array}$ & $t / Z$ & $P$-value \\
\hline $\mathrm{TC}(\mathrm{mmol} / \mathrm{L})$ & $4.26 \pm 0.52$ & $4.23 \pm 1.00$ & $0.206^{\mathrm{a}}$ & 0.839 \\
\hline TG (mmol/L) & $1.16 \pm 0.47$ & $1.27 \pm 1.42$ & -0.271 & 0.787 \\
\hline $\mathrm{HDL}(\mathrm{mmol} / \mathrm{L})$ & $1.38 \pm 0.34$ & $1.19 \pm 0.37$ & 2.322 & 0.021 \\
\hline LDL (mmol/L) & $2.39 \pm 0.39$ & $2.56 \pm 0.82$ & -1.910 & 0.067 \\
\hline
\end{tabular}

Notes: ${ }^{\mathrm{a} C}$ Comparison between OM group and NOM metastases group by nonparametric sum up tests. $P<0.05$ was considered statistically significant.

Abbreviations: OM, ocular metastasis; NOM, non-ocular metastasis; TC, total cholesterol; TG, triglyceride; HDL, high-density lipoprotein; LDL, low-density lipoprotein.

specificity. Therefore, early diagnosis of ocular metastases occurring in CRC patients is not easy, but nevertheless it is rather important. Techniques to detect serum tumor markers have advantages including repeatability, noninvasiveness, and low cost. At this point, the use of serum lipid levels as risk factors for different types of cancer have been investigated, and the results have indicated that as screening tests these levels may have some utility (Table 5). Given these findings of correlations between blood lipids and cancer, we 
Table 4 The binary logistic regression results of HDL in different groups

\begin{tabular}{|l|l|l|l|l|}
\hline Group & B & OR & OR (95\% CI) & P-value \\
\hline NLNM & 1.380 & 3.974 & $1.425-11.084$ & 0.008 \\
Male & 1.370 & 3.937 & $1.219-12.712$ & 0.022 \\
NLNM + male & 1.674 & 5.332 & $1.524-18.656$ & 0.009 \\
Total & 1.158 & 3.184 & $1.184-8.563$ & 0.022 \\
\hline
\end{tabular}

Note: $P<0.05$ represented statistical significant.

Abbreviations: $B$, coefficient of regression; NLNM, non-lymph node metastasis.

analyzed four serum lipid parameters in OM and NOM patients to begin to clarify the risk factors for ocular metastases from CRC.

We identified HDL as a risk factor for OM in patients with CRC after measuring the levels of serum TC, TG, HDL, and LDL. We found that the serum HDL level was significantly different in patients with and without ocular metastases, and it was higher in the OM group.
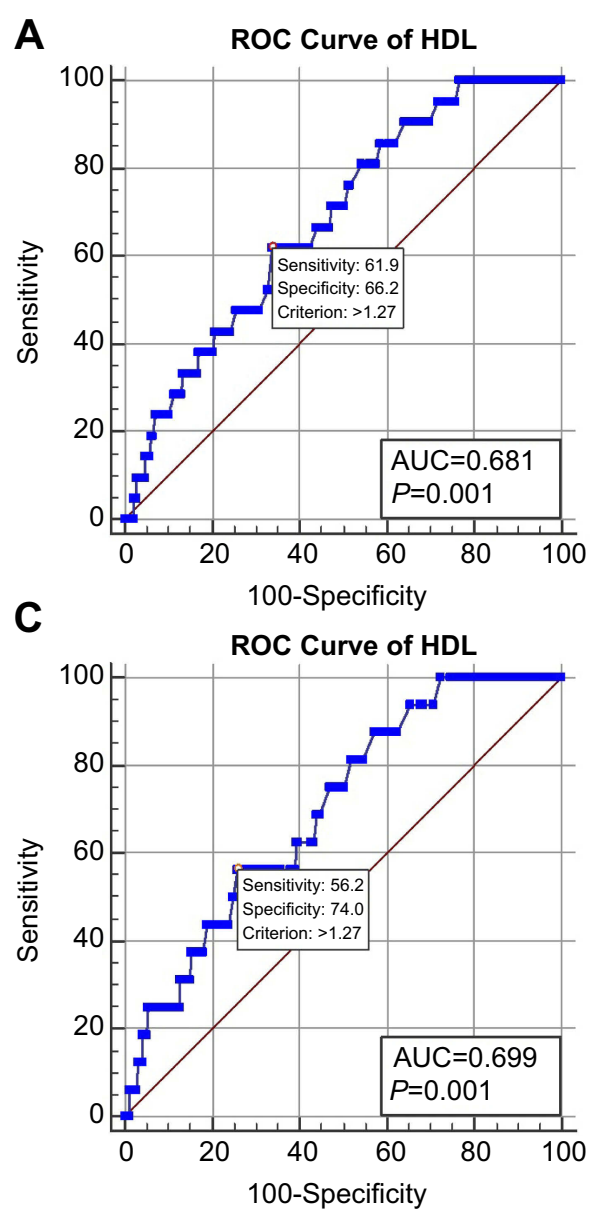

High-density lipoprotein cholesterol (HDL) is well known as a protective lipid for atherosclerosis, and can transport excess cholesterol from the periphery to the liver. Studies have demonstrated that it has antioxidant, anti-inflammatory, and anti-thrombotic effects, but that it also has a correlation with cancer incidence ${ }^{21-24}$ such that that HDL increases cancer risk by $36 \%$ per $10 \mathrm{mg} / \mathrm{L}$ increase. There is also a positive correlation between HDL level and the prognosis of numerous cancers. $^{21-24}$ Moreover, HDL may directly or indirectly affect the incidence of colorectal tumors through several possible mechanisms. ${ }^{25-29}$ HDL has been associated with increased levels of anti-inflammatory cytokines such as interleukin 10 (IL-10), that reduce production of pro-inflammatory agents such as IL-6 and tumor necrosis factor receptors, thereby inhibiting cell growth and proliferation as well as promoting apoptosis. ${ }^{25-27}$ In addition, HDL levels are closely related to age-related macular degeneration (AMD), ${ }^{30-32}$ dry eye (DE), ${ }^{33,34}$ and cardiovascular disease (CVD). ${ }^{35}$ And some

B

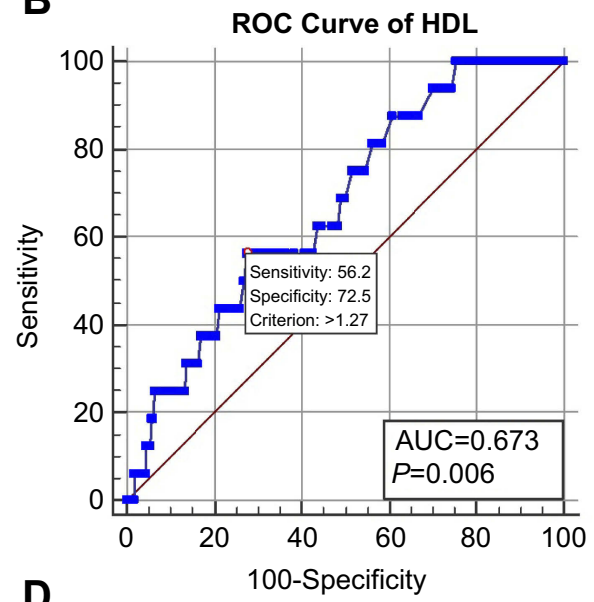

D

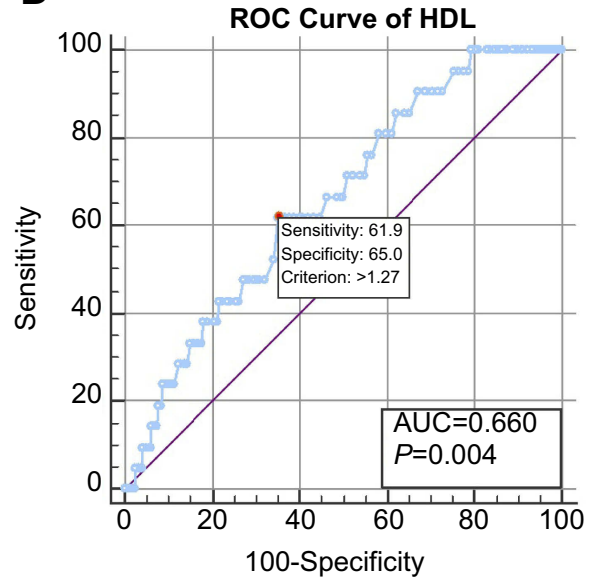

Figure 2 Clinical features of colorectal cancer patients involved.

Abbreviations: AUC, area under the curve; HDL, high-density lipoprotein; ROC, receiver operating curve. 
Table 5 The serum lipids as risk factors of different kinds of cancer

\begin{tabular}{|c|c|c|c|}
\hline Author & Year & Cancer & Serum lipids \\
\hline Liu et $\mathrm{al}^{36}$ & 2011 & Lymph node & LDL \\
\hline Saito et $\mathrm{al}^{39}$ & 2013 & Liver cancer & LDL \\
\hline His et $\mathrm{al}^{40}$ & 2014 & Breast cancer & TC, HDL, ApoAI \\
\hline Chandler et $\mathrm{al}^{41}$ & 2016 & Colorectal cancer & HDL,TC, ApoB- 100 \\
\hline Chandler et $\mathrm{al}^{4 \mid}$ & 2016 & Lung cancer & $\mathrm{HDL}$ \\
\hline Jiang et $\mathrm{a}^{42}$ & 2017 & Breast cancer & PC, TG, DG, PE \\
\hline Bastani et $\mathrm{al}^{43}$ & 2017 & Ovarian cancer & $\mathrm{HDL}$ \\
\hline
\end{tabular}

Abbreviations: LDL, low-density lipoprotein; TC, total cholesterol; HDL, high-density lipoprotein; ApoAI, ApolipoproteinAI; ApoB-100, ApolipoproteinB-I00; PC, phosphatidylcholine; TG, triacylglycerol; DG, diacylglycerol; PE, phosphatidylethanolamine.

reports have suggested that high HDL levels are associated with an increased risk of $\mathrm{AMD}^{30-32}$ whereas low HDL levels are relevant to DE and CVD. ${ }^{33-35}$ In our study, the CRC patients with ocular metastases had increased serum levels of HDL, which is opposite to the correlation between HDL and the incidence of $\mathrm{CRC}$, but in line with the changes in some ocular diseases.

The levels of serum lipids also are correlated with some clinical features such as lymph node metastases and gender. Liu et $\mathrm{al}^{36}$ reported that patients with high serum LDL levels and an elevated LDC/HDL ratio might be prone to developing lymph node metastases. Balder et $\mathrm{al}^{37}$ observed gender- and age-related differences in plasma lipid profiles. According to a study of 11,864 persons (9,602 males and 2,262 females by Tharu BP et $\mathrm{al}^{38}$ ) there are gender and racial factors affecting cholesterol levels, and females tend to have higher variations in cholesterol level than do males. So we classified the CRC patients' characteristics and found for those two factors, the values of TC, HDL, and LDL showed significant differences between the LNM and NLNM groups, as well as between the male and female patients. Specifically, the LNM patients and female patients presented with higher TC, HDL, and LDL levels.

Following the analyses of serum TC, TG, HDL, and LDL levels in these colorectal cancer patients, we suggested that increased HDL levels were a risk factor for ocular metastases. However, in female patients with $\mathrm{OM}$ and NOM, the difference in the levels between the individuals was not significant.

The results of our study support the hypothesis that HDL is a risk factor for OM in patients with CRC, with a cutoff value of $1.27 \mathrm{mmol} / \mathrm{L}$. The AUC of the ROC curves from all of the patients was 0.660 . This data provided relatively low accuracy levels for distinguishing $\mathrm{OM}$ patients with colorectal cancer, and clarified the diagnostic value of HDL for predicting OM. However, compared with other available diagnostic methods, the serum HDL test is repeatable, inexpensive, simple, and fast, and it would enable more patients to monitor their condition and to track the risks of ocular metastases. Although it has limited sensitivity and specificity according to our study, monitoring of serum HDL still has value for predicting OM in CRC patients. By combining serum HDL data with traditional diagnostic methods such as CT and MRI, the future development of a more reliable protocol to diagnose patients with OM should be feasible.

\section{Limitations}

Although the present results were statistically significant, our study is limited to some extent. Firstly, as a retrospective study with some patients excluded from the group, there may have been deviations in the analysis. Secondly, the concentration of lipids in the serum was collected at the time of diagnosis, and this therefore did not provide key data that may have correlated with the tumors' progression and growth. Thirdly, the size of samples, especially of the OM groups, was small in this study compared to the entire population of subjects. This makes conclusions based on the outcomes of the OM group relatively poorly convincing. In this small sample, none of the OM patients developed lymph node metastases, making the statistical results here less than convincing for CRC patients who have already developed lymph node metastases. Finally, all the patients here were diagnosed and treated at the same hospital, which raises the possibility of the study being marred by a selection bias. Thus, it will be important to verify the results of this study by large sample prospective, multi-center studies.

\section{Conclusion}

In summary, We found that the concentration of serum HDL is significantly elevated in CRC patients with OM. Thus, high serum HDL levels may be a risk factor for developing OM in CRC patients. For newly diagnosed colorectal patients, if their serum HDL is $>1.27 \mathrm{mmol} / \mathrm{L}$, radiological examinations such as a head CT or MRI studies should be obtained, given that elevated HDL has a certain predictive value for ocular metastases in colorectal cancer patients.

\section{Disclosure}

The authors report no conflicts of interest in this work. 


\section{References}

1. Roncucci L, Mariani F. Prevention of colorectal cancer: how many tools do we have in our basket? Eur J Intern Med. 2015;26 (10):752-756. doi:10.1016/j.ejim.2015.08.019

2. Siegel R, DeSantis C, Jemal A. Colorectal cancer statistics, 2014. CA Cancer J Clin. 2014;64(2):104-117. doi:10.3322/caac.21220

3. World Cancer Research Fund/American Institute for Cancer Research. Food, Nutrition, Physical Activity, and the Prevention of Cancer: A Global Perspective. Washington (DC): AICR; 2007:280-288.

4. Jemal A, Bray F, Center MM, et al. Global cancer statistics. $C A$ Cancer J Clin. 2011;61(2):69-90. doi:10.3322/caac.20107

5. Hess KR, Varadhachary GR, Taylor SH, et al. Metastatic patterns in adenocarcinoma. Cancer. 2006;106(7):1624-1633. doi:10.1002/ cncr. 21730

6. Jardel P, Sauerwein W, Olivier T, et al. Management of choroidal metastases. Cancer Treat Rev. 2014;40(10):1119-1128. doi:10.1016/j. ctrv.2014.09.006

7. Georgalas I, Paraskevopoulos T, Koutsandrea C. et al. Ophthalmic metastasis of breast cancer and ocular side effects from breast cancer treatment and management: mini review. Biomed Res Int. 2015:1-8. doi: $10.1155 / 2015 / 574086$

8. Zhong W, Yu Z, Zhan J, et al. Association of serum levels of CEA, CA199, CA125, CYFRA21-1 and CA72-4 and disease characteristics in colorectal cancer. Pathol Oncol Res. 2015;21(1):83-95. doi:10.1007/s12253-014-9791-9

9. Liu X, Cai H, Wang Y. Prognostic significance of tumour markers in chinese patients with gastric cancer. ANZ J Surg. 2014;84(6):448453. doi:10.1111/j.1445-2197.2012.06287.

10. Zhang X, Zhao XW, Liu DB, et al. Lipid levels in serum and cancerous tissues of colorectal cancer patients. World J Gastroenterol. 2014;20 (26):8646-8652. doi:10.3748/wjg.v20.i26.8646

11. Zamanian-Daryoush M, Lindner D, Tallant TC, et al. The cardioprotective protein apolipoprotein A1 promotes potent anti-tumorigenic effects. J Biol Chem. 2013;288(29):21237-21252. doi:10.1074/jbc. M113.468967

12. Ma XL, Gao XH, Gong ZJ, et al. Apolipoprotein A1: a novel serum biomarker for predicting the prognosis of hepatocellular carcinoma after curative resection. Oncotarget. 2016;7(43):70654-70668. doi:10.18632/oncotarget.12203

13. Sirniö P, Väyrynen JP, Klintrup K, et al. Decreased serum apolipoprotein A1 levels are associated with poor survival and systemic inflammatory response in colorectal cancer. Sci Rep. 2017;7(1). doi:10.1038/s41598-017-05415-9

14. van Duijnhoven FJ, Bueno-De-Mesquita HB, Calligaro M, et al. Blood lipid and lipoprotein concentrations and colorectal cancer risk in the European prospective investigation into cancer and nutrition. Gut. 2011;60:1094-1102. doi:10.1136/gut.2011. 237727

15. Kitahara CM, Berrington de González A, Freedman ND, et al. Total cholesterol and cancer risk in a large prospective study in Korea. J Clin Oncol. 2011;29:1592-1598. doi:10.1200/JCO.2010.31.5200

16. Torre LA, Bray F, Siegel RL, et al. Global cancer statistics, 2012. CA Cancer J Clin. 2015;65:87-108. doi:10.3322/caac.21262

17. Tauriello DVF, Calon A, Lonardo E, et al. Determinants of metastatic competency in colorectal cancer. Mol Oncol. 2017;11(1):97-119. doi:10.1002/1878-0261.12018

18. Linares P, Castanon C, Vivas S, et al. Bilateral choroidal metastasis as the initial manifestation of a rectal cancer. $J$ Gastroenterol Hepatol. 2004;19(6):726-727. doi:10.1111/j.1440-1746.2004.03465.x

19. Kuo IC, Haller JA, Maffrand R, et al. Regression of a subfoveal choroidal metastasis of colorectal carcinoma after intravitreous bevacizumab treatment. Arch Ophthalmol. 2008;126(9):1311-1313. doi:10.1001/archophthalmol.2008.2

20. Shields CL, Shields JA, Gross NE, et al. Survey of 520 eyes with uveal metastases. Ophthalmology. 1997;104(8):1265-1276.
21. Chi PD, Liu W, Chen H, et al. High-density lipoprotein cholesterol is a favorable prognostic factor and negatively correlated with C-reactive protein level in non-small cell lung carcinoma. PLoS One. 2014;9:e91080. doi:10.1371/journal.pone.0091080

22. Tamura $\mathrm{T}$, Inagawa $\mathrm{S}$, Hisakura $\mathrm{K}$, et al. Evaluation of serum high-density lipoprotein cholesterol levels as a prognostic factor in gastric cancer patients. J Gastroenterol Hepatol. 2012;27:1635-1640. doi:10.1111/j.1440-1746.2012.07189.x

23. Kotani K, Sekine Y, Ishikawa S, et al. High-density lipoprotein and prostate cancer: an overview. J Epidemiol. 2013;23:313-319.

24. Jafri H, Alsheikh-Ali AA, Karas RH. Baseline and on-treatment high-density lipoprotein cholesterol and the risk of cancer in randomized controlled trials of lipid-altering therapy. $\mathrm{J} \mathrm{Am} \mathrm{Coll} \mathrm{Cardiol.}$ 2010;55:2846-2854. doi:10.1016/j.jacc.2009.12.069

25. Esteve E, Ricart W, Fernandez-Real JM. Dyslipidemia and inflammation: an evolutionary conserved mechanism. Clin Nutr. 2005;24:16-31. doi:10.1016/j.clnu.2004.08.004

26. Kim S, Keku TO, Martin C, et al. Circulating levels of inflammatory cytokines and risk of colorectal adenomas. Cancer Res. 2008;68:323-328. doi:10.1158/0008-5472.CAN-07-2924

27. van Exel E, Gussekloo J, de Craen AJ, et al. Low production capacity of interleukin-10 associates with the metabolic syndrome and type 2 diabetes: the Leiden 85-Plus Study. Diabetes. 2002;51:1088-1092. doi:10.2337/diabetes.51.4.1088

28. Kontush A, de Faria EC, Chantepie S, et al. A normotriglyceridemic, low HDL-cholesterol phenotype is characterized by elevated oxidative stress and HDL particles with attenuated antioxidative activity. Atherosclerosis. 2005;182:277-285. doi:10.1016/j.atherosclerosis.2005.03.001

29. Vekic J, Kotur-Stevuljevic J, Jelic-Ivanovic Z, et al. Association of oxidative stress and PON1 with LDL and HDL particle size in middle-aged subjects. Eur J Clin Invest. 2007;37:715-723. doi:10.1111/j.1365-2362.2007.01849.x

30. Cougnard-Grégoire A, Delyfer MN, Korobelnik JF, et al. Elevated high-density lipoprotein cholesterol and age-related macular degeneration: the Alienor study. PLoS One. 2014;9(3):e90973. doi:10.1007/s10529-017-2417-z

31. Colijn JM, Hollander AID, Demirkan A, et al. Increased high density lipoprotein-levels associated with age-related macular degeneration. Evidence from the EYE-RISK and E3 consortia. Ophthalmology. 2019 ;126(3):393-406. doi: 10.1016/j.ophtha.

32. Cheung CMG, Gan A, Fan Q, et al. Plasma lipoprotein subfraction concentrations are associated with lipid metabolism and age-related macular degeneration. J Lipid Res. 2017;58(9):1785-1796. doi:10.1194/jlr. M073684

33. Rathnakumar K, Ramachandran K, Baba D, et al. Prevalence of dry eye disease and its association with dyslipidemia. J Basic Clin Physiol Pharmacol. 2018;29(2):195-199. doi:10.1515/jbcpp-2017-0001

34. Chun YH, Kim HR, Han K, et al. Total cholesterol and lipoprotein composition are associated with dry eye disease in Korean women. Lipids Health Dis. 2013;12:84. doi:10.1186/1476-511X-12-84

35. Schaefer EJ, Anthanont P, Diffenderfer MR, et al. Diagnosis and treatment of high density lipoprotein deficiency. Prog Cardiovasc Dis. 2016;59(2):97-106. doi:10.1016/j.pcad.2016.08.006

36. Liu YL, Qian HX, Qin L, et al. Serum LDL-C and LDL-C/HDL-C ratio are positively correlated to lymph node stages in males with colorectal cancer. Hepatogastroenterology. 2011;58(106):383-387.

37. Balder JW, de Vries JK, Nolte IM, et al. Lipid and lipoprotein reference values from 133,450 Dutch Lifelines participants: ageand gender-specific baseline lipid values and percentiles. J Clin Lipidol. 2017;11(4):1055-1064. doi:10.1016/j.jacl.2017.05.007

38. Tharu BP, Tsokos CP. A statistical study of serum cholesterol level by gender and race. J Res Health Sci. 2017;17(3):e00386.

39. Saito N, Sairenchi T, Irie F, et al. Low serum LDL cholesterol levels are associated with elevated mortality from liver cancer in Japan: the Ibaraki Prefectural health study. Tohoku J Exp Med. 2013;229 (3):203-211. 
40. His M, Zelek L, Deschasaux M, et al. Prospective associations between serum biomarkers of lipid metabolism and overall, breast and prostate cancer risk. Eur J Epidemiol. 2014;29(2):119-132. doi:10.1007/s10654-014-9884-5

41. Chandler PD, Song Y, Lin J, et al. Lipid biomarkers and long-term risk of cancer in the Women's Health Study. Am J Clin Nutr. 2016;103(6):1397-1407. doi:10.3945/ajen.115.124321
42. Jiang N, Zhang G, Pan L, et al. Potential plasma lipid biomarkers in early-stage breast cancer. Biotechnol Lett. 2017;39(11):1657-1666. doi:10.1007/s10529-017-2417-z

43. Bastani A, Asghary A, Heidari MH, et al. Evaluation of the sensitivity and specificity of serum level of prostasin, CA125, $\mathrm{LDH}, \mathrm{AFP}$, and hCG $+\beta$ in epithelial ovarian cancer patients. Eur J Gynaecol Oncol. 2017;38(3):418-424.

\section{Publish your work in this journal}

Cancer Management and Research is an international, peer-reviewed open access journal focusing on cancer research and the optimal use of preventative and integrated treatment interventions to achieve improved outcomes, enhanced survival and quality of life for the cancer patient.
The manuscript management system is completely online and includes a very quick and fair peer-review system, which is all easy to use. Visit http://www.dovepress.com/testimonials.php to read real quotes from published authors. 